\title{
Dissimilation at the Interface: Nominalization as the Key to a Longstanding Puzzle
}

\author{
Jeffrey Punske \\ Southern Illinois University, USA
}

\begin{abstract}
The narrow goal is to provide a complete account of the doubl-ing effect (Ross 1972) within a Minimalist and Distributed Morphology
\end{abstract}

\footnotetext{
$\S$ I am indebted to a number of helpful hands who have helped shape this work too many to properly thank. I would like to express special gratitude to audiences at the Arizona Linguistics Circle, the University of Kansas, the University of Illinois, and Nominals at the Interface at Songang University along with Heidi Harley, Jason Haugen, Scott Jackson, Vicki Carstens, Stacey Sloboda, Ulrich Reichhard, Bridget Samuels, and Carrie Gillon of Quick Fox Consulting. All errors and oversights remain my own.
}

Jeffrey Punske

Assistant Professor, Southern Illinois University, Carbondale, USA

Email: punske@siu.edu

Received 24 September, 2018; Revised 8 December, 2018; Accepted 10 January, 2019

Copyright (C) 2019 Language Research Institute, Sejong University Journal of Universal Language is an Open Access Journal. All articles are distributed online under the terms of the Creative Commons Attribution Non-Commercial License (http://creativecommons.org/licenses/by-nc/3.0) which permits unrestricted non-commercial use, distribution, and reproduction in any medium, provided the original work is properly cited. 
40 Dissimilation at the Interface: Nominalization as the Key to a Longstanding Puzzle

approach. In particular, I examine the effect within nominals and show that the pattern can be fully captured via the interaction of previous analyses: structural differences based on whether the nominals are complex event nominals (Grimshaw 1990), local dislocation of the -ing affix (Punske 2016), and Distinctness (Richards 2010). I show that this account is fully compatible with full facts of the phenomenon and discuss other possible dissimilation effects that may be explored in the future.

Keywords: dissimilation, morphology, syntax, local dislocation, distinctness

\section{Introduction}

In this paper, I explore the mechanisms required to derive the morphosyntactic dissimilation pattern (see Neelman \& van de Koot 2006, Richards 2010, Nevins 2012, and citations therein). The primary focus is on the English doubl-ing effect, but some discussion of the Japanese Double- $o$ Constraint, restrictions on Mandarin final particles, and Dutch er repetition is also provided. The account I provide extends Richards' (2010) Distinctness condition to account for pure linearization effects. Like Richards (2010), and numerous other previous accounts, these effects are modulated via multiple spell-out.

The primary focus of the paper is related to the English morpheme -ing, where adjacent -ing affixed forms are sometimes, but not always, ungrammatical, as first described by Ross (1972). ${ }^{1}$ This phenomenon has received considerable attention in the literature (with subsequent additional descriptions and discussion by Milsark (1972), Emonds (1973), Pullum (1974), Milsark (1988), Emonds

1 Emonds (1973) credits a paper presented by Arthur Speers at the First California Linguistics Conference for describing some aspects of the doubl-ing effect, but no further citation information is given. 
(1991), Yip (1998), Pullum \& Zwicky (1999), Milsark (2006), Richards (2010), Nevins (2012), along with related discussions by Menn \& MacWhinney (1984), Borer (1990), Hiraiwa (2014), Punske (2016), among others, but, as I argue, still lacks a satisfactory solution. I argue that, by examining nominalizations, which are commonly and/or explicitly ignored within this literature, a solution becomes apparent. I show that the doubl-ing effect is a complex interaction of local dislocation (as described in Punske 2016), differences between complex event nominals (Grimshaw 1990) and other nominals, and cyclic derivation (Chomsky 2001, 2004, 2005, and many other related works). While cyclic derivation is sufficient to explain the doubl-ing effect in the verbal domain, it is insufficient to capture the effect alone in nominalization.

The basic phenomenon can be seen most clearly in the contrast between (1) and (2) (cf. Ross 1972), where the adjacent -ing marked forms in (2) seem to turn an otherwise grammatical sentence ungrammatical.

(1) It continued raining.

(2) *It was continuing raining. ${ }^{2}$

(Ross 1972: 61)

(3) *Anyone keeping eating swordfish

(Ross 1972: 67)

(4) John was enjoying reading the book

(Milsark 1988: 624)

(5) John has been regretting reading the book

(Milsark 1988: 624)

Similarly, we can examine the contrast of examples (2) and (3)

2 A reviewer notes that dialectal variation may exist for examples like this. The overall pattern described here remains robust, but is certainly subject to speaker variation. 
42 Dissimilation at the Interface: Nominalization as the Key to a Longstanding Puzzle

and those of (4) and (5) where, in the latter examples, the adjacency of the -ing marked forms does not result in ungrammaticality.

I examine understudied evidence from the doubl-ing effect in English nominals to show that the effect has been thus far inadequately described and accounted for. In particular, I examine the relationship of -ing marked adjectives and nominals to show that a more refined analysis of the effect is needed. In particular, a key distinction is shown to exist between the grammaticality of complex event nominals (in the sense of Grimshaw 1990) and the grammaticality of other nominal. The doubl-ing effect is found in event nominals, but not in other -ing marked nominals.

(6) *The baffling destroying of the city...

(Punske 2016: 87)

(7) The daring killing of Oswald still sparks the interest of conspiracy theorists.

In particular, I argue, in contrast to the previous literature, that the doubl-ing effect need not be reduced to any specialized constraint, but instead entirely falls out from the interplay between the postsyntactic movement of vocabulary items (e.g., Embick 2007, Punske 2016) and, following Hiraiwa (2010a, 2010b, 2014), the presence of multiple, distinct spell-out domains, as is required in phase theory (Chomsky 2001 and related works). Event nominals, like those in (6), involve local dislocation of the -ing affixes, potentially subjecting them to the doubl-ing effect. Non-event nominals, like those in (7), do not involve local dislocation of their affixes and thus will not trigger the doubl-ing effect, even when modified by an adjective with a locally dislocating -ing affix. The analysis is to be understood in terms of Distinctness (Richards 2010), provided that it may apply at, at least, two separate points in the derivation: one prior 
to vocabulary insertion (as in Richards 2010) and one after vocabulary insertion, at the point of linearization/local dislocation.

\subsection{Describing Doubl-ing}

As noted, in the simplest terms, the doubl-ing phenomenon can be described as follows: adjacent -ing marked forms are sometimes ungrammatical and sometimes acceptable. The effect was first described by Ross (1972) along with the subsequent discussions mentioned previously. Most of these descriptions concentrate either on the differences between the (verbal) aspectual -ing and the gerundive -ing (such as claims that doubl-ing does not apply to nominals) or the presence of some hidden functional structure or category (such as PRO or CP) blocking the effect. ${ }^{3}$ The general pattern as described in this literature is seen in the examples presented here and throughout the rest of this subsection. ${ }^{4}$

Contrasts like those in (8) and (9) below illustrate that it is adjacent -ing marked forms that seem to trigger ungrammaticality in the relevant English sentences.

(8) *The police are stopping drinking (publicly) on campus.

(Milsark 1972: 542)

(9) The police are stopping (public) drinking on campus.

(Milsark 1972: 452)

\footnotetext{
${ }^{3}$ Here is a list of abbreviations used in this article: $\mathrm{CP}=$ Complementizer Phrase; $\mathrm{DM}=$ Distributed Morphology; DP $=$ Determiner Phrase; $\mathrm{e}=$ empty category; EXPL $=$ Expletive; Ger $=$ Gerund $;$ LOC $=$ locative $; \mathrm{PF}=$ Phonological Form; QUANT $=$ Quantifier.

${ }^{4}$ See Walter (2007: 57) for discussion of and quantitative support for the phenomenon.
} 
44 Dissimilation at the Interface: Nominalization as the Key to a Longstanding Puzzle

Examples like (8) can be contrasted with their non-ing marked counterparts, which are perfectly acceptable, as in (10) below:

(10) The police stopped drinking (publicly) on campus.

(cf. Ross 1967: 73)

This is arguably something like a morphosyntactic application of the Obligatory Contour Principle (Leben 1973), which was originally proposed in the domain of phonology; syntactic versions of such a constraint can be found in work by Mohanan (1994), Ackema (2001), and Hiraiwa (2010a). However, as noted, it is not the case that all examples of adjacent -ing marked forms result in ungrammatical sentences. This is seen in examples (4) and (5) (repeated as (11) and (12) below):

(11) John was enjoying reading the book

(Milsark 1988: 624)

(12) John has been regretting reading the book (Milsark 1988: 624)

This suggests that there is some (hidden) structure that distinguishes grammatical examples from ungrammatical ones. For Milsark (1988), all examples of adjacent -ing marked forms are ungrammatical, thus in (11) and (12) something must be intervening; he argues that this is PRO. Nevins (2012) suggests that it is the CP complex associated with PRO that intervenes.

Previous accounts, such as Milsark (1972), Emonds (1973), and Pullum \& Zwicky (1999), argued that the critical difference between the grammatical and ungrammatical sentences is essentially between nouns and verbs - the offending property is found in verbs but not in nouns. However, the doubl-ing effect can be observed within nominals, as noted in Punske (2016), (see Richards 2010: 65-67 for some 
related facts) where gerunds and -ing modified adjectives interact with respect to the doubl-ing effect, as seen in the examples below:

(13) *The baffling destroying of the city... (Punske 2016: 87)

(14) *[John's confusing leaving] interrupted the party.

(15) *? ${ }^{\text {? }}$ The repeated annoying stopping of the car] by the taxi driver made Susan ill.

Such examples strongly suggest that category-based accounts should be viewed with skepticism. More aggressive accounts, such as Milsark (1988) or Nevins (2012), which hold that all adjacent -ing marked forms are ungrammatical, can account for the examples in (13)-(15), but will struggle to account for examples such as (7) (repeated (16) below), since there is no reasonable intervening silent structure that would intervene between daring and killing but not baffling and destroying.

(16) The daring killing of Oswald still sparks the interest of conspiracy theorists.

Similarly, we may note that some potentially ambiguous nominal constructions lose potential interpretations when in the presence of an -ing marked adjective. Consider the following examples (17)-(19) below (based generally on an example from Pullum \& Zwicky 1999: 255):

(17) The amazing building...

a. *The amazing process by which the Eiffel tower was built

b. The amazing building that is the Eiffel tower 
46 Dissimilation at the Interface: Nominalization as the Key to a Longstanding Puzzle

(18) The amazing building towers over the city.

(19) *The amazing building of the tower took 18 years.

Note that while forms like building are ambiguous between the eventive (gerund) interpretation and the concrete result (non-gerund) interpretation in many contexts, that ambiguity is lost when there is a modifying -ing marked adjective. This, I argue, is another instantiation of the doubl-ing effect-just in a very different form.

There are a number of reasons to believe that the -ings found in the different readings of (17) are fundamentally distinct. Even if they are not distinct morphemes, there is certainly distinct structure associated with the readings. Indeed, as discussed in the next section, diagnostics from Grimshaw (1990) show that the distinct interpretations of building-type nominals must be associated with different types of nominal constructions. Within the nominal domain, the doubl-ing effect only occurs when a nominal is eventive in the sense of Grimshaw (1990), ${ }^{5}$ a fact that, when combined with Punske's (2016) approach to regularity, can be readily explained.

\section{Modeling Doubl-ing}

The analysis I present removes the need for any specialized constraint on dissimilation. I argue that the doubl-ing effect is a byproduct of the interaction between the local dislocation (Embick 2007a) of -ing, as modified and defined in Punske (2016), and linearization (Kanye 1994). This idea that linearization is sensitive to

\footnotetext{
5 I use the terms 'eventive' and 'event nominals' to refer to 'complex event nominals' throughout.
} 
the non-uniqueness of adjacent elements is not unique to this work (see for instance Richards 2001, 2010); however, the particular implementation is novel. This analysis results in a supplement to Richards' (2010) Distinctness, arguing that Distinctness must apply, at least, at two separate points in the derivation: once prior to vocabulary insertion and once at the point of local dislocation.

Subsection 2.1 shows how this analysis applies within a nominalization, arguing that there must be (at least) two distinct -ings: one that is subject to local dislocation and one that is not. Subsection 2.2 revisits the more canonically discussed doubl-ing effect within the verbal domain and discusses how those cases are captured through the presence or absence of phase boundaries (cf. Nevins 2012).

\subsection{The Double-ing Effect in Nominalizations}

Recall, that, much like the doubl-ing effect in the verbal domain (as described in Ross 1972 and onward), ungrammaticality does not always occur when an -ing modified adjective and an -ing modified nominal are adjacent to each other:

(20) *The baffling destroying of the city...

(21) Ruby's daring killing of Oswald still sparks the interest of conspiracy theorists.

Such examples are fundamental to the present analysis because examples like (20) cannot be accounted for by any previous account of the doubl-ing effect, except Milsark's (1988) global filter. However, such examples still pose a challenge for Milsark's analysis (or an extended version, in the sense of Nevins 2012), since there is no theoretic basis for assuming an intervening PRO (or CP complex) between daring and killing in (21). 
48 Dissimilation at the Interface: Nominalization as the Key to a Longstanding Puzzle

A related puzzle also discussed previously in (17) is illustrated by (22) below:

(22) The amazing building...

Only the non-event interpretation is available in (22), where building must be interpreted as a concrete result. I take this to mean that the forms of -ing in the two different interpretations of building are distinct, with one (the gerund/eventive) undergoing local dislocation and thus participating in the doubl-ing effect and the other being an idiosyncratic form associated with particular nominal roots. Arguments for this largely follow from Grimshaw's (1990) discussion of nominalization. The pattern to note here is that doubl-ing forms are acceptable when the nominal can be indefinite; thus, (25) is acceptable while (23) and (24) they may not be.

(23) *I'd hate to see a destroying of the town.

(24) *The developer is just waiting for a building of a shopping mall nearby.

(25) The police are puzzled by a killing of the priest in such a quaint little town.

This suggests that the doubl-ing effect is active in event nominals, but not generally in nominals. This fits with Grimshaw's (1990) discussion of nominalization; she notes that "event NPs cannot be indefinite" (p. 55) and "gerundive nominals pattern perfectly as complex event nominals" (p. 56).

The behavior of forms like killing appears to break this generalization to some degree. However, there are compelling reasons to believe 
that killing is not an event nominal or gerund. For example, Grimshaw (1990) notes that event nominals never pluralize and never occur predicatively. Unlike destroying or the event interpretation of building and other related event nominals, killing also may be pluralized and occur predicatively.

(26) The daring killings of public officials ignited the revolution.

(27) That was the killing of the rabbits.

Contrast (26) and (27) with (28) and (29) below:

(28) *The shootings of rabbits are illegal.

(Grimshaw 1990: 56)

(29) *That was the shooting of the rabbits. (Grimshaw 1990: 56)

It is fair for us to question what separates a killing-type nominal from a building-type nominal (or perhaps even more puzzlingly, a shooting-type nominal). I suggest that killing as an achievement predicate retains an encyclopedic event interpretation even when an event interpretation is not provided by the syntax; however, this suggestion is tentative. Critically, the distributional syntax and its interpretation exhibit a mismatch. Shooting and building, which are activity predicates, do not have such an interpretation, unless the nominal structure provides it. Thus, it is reasonable to argue that the "non-event" interpretation of killing is available to rescue otherwise illicit forms. I therefore argue that killing and the concrete result form building are structurally different from event nominals/gerunds like those discussed by Grimshaw. In the model presented in this section, specific and category-determining affixes like -ing in killing and the relevant reading of building, which are lexically determined, 
are not subject to local dislocation because they are lexically selected and thus do not participate in the doubl-ing effect. ${ }^{6}$

Punske (2016) develops a distinct model of allomorphy based on English nominalization patterns, arguing for a distinction between local dislocation, Lowering, and head movement in the narrow syntax. In this analysis, regular exponents (morphemes that only exhibit regular phonology, but not allomorphy — such as the English nominalizer -ing) are the product of local dislocation. Suppletive (non-regular allomorphic) morphemes must be joined with their target forms prior to Vocabulary Insertion either by head movement in the narrow syntax or Lowering.

For Punske (2016), the structure of a derived nominal and the structure of a nominal gerund/mixed nominalization are identical. Thus, adjacency alone is not enough to derive the allomorphy. Allomorphy in derived nominals is driven by cyclic head-movement of the root through the $n^{0}$ to reach $k$ (or an alternate flavor of $n$ analysis discussed). For Punske (2016), $k$ is required for the nominal to assign case to its object. If no $k$ is present, no special allomorphy will occur and -ing will be inserted.

6 Jason Haugen (personal communication) notes the expletive fucking appears to be able to circumvent the doubl-ing phenomenon (both in that it is an -ing form itself and, possibly, that it can rescue otherwise illicit forms).

i) I'm fucking enjoying reading this paper. (= I'm really enjoying it)

ii) I'm enjoying fucking reading this paper. (= I'm enjoying reading it vs. hearing it presented orally)

iii) I'm fucking enjoying fucking reading this paper. (= I'm really enjoying reading it vs. hearing it presented orally)

iv) ?It is continuing fucking raining.

The most plausible analysis for this behavior is related through an analysis that links prosody (given the marked prosody that the introduction of fucking requires) and phases, such as Dobashi (2003), Legate (2003), Adger (2007), Samuels (2011); among others. 
Punske (2016) argues that nominal gerunds/mixed nominalizations exhibit complete regularity because their nominalizing head and root do not meet in narrow syntax, but instead the nominalizing head $\left(-i n g^{7}\right)$ is inserted blindly at Vocabulary Insertion and finds the root later through local dislocation. The lack of association between the root and the nominalizer at Vocabulary Insertion is what forces total regularity. This construction contrasts with derived nominals, which ex1hibit an array of irregular behaviors.

What separates Punske's proposal from a number of others is that it takes argument-taking derived nominals to be structurally more complex than nominal gerunds/mixed nominalizations. For Punske (2016), the critical difference between a derived nominal (subject to allomorphy) and a gerund (surfacing with a regular -ing) is the cyclic head movement found in derived nominals. This movement is triggered either by a high $k \mathrm{P}$ or by a particularly "flavor" of $n-$ Punske (2016) offers both alternatives. Under this account, allomorphy is driven by visibility at spell out/vocabulary insertion; allomorphy is only possible when head movement has occurred. When movement has not occurred, a default form (like -ing will be inserted). In the case of English nominals, this default form must then locally dislocate because it is not phonological free.

Many of the particulars of this analysis are not relevant to our present discussion, though I later will greatly simplify the mechanics of local dislocation proposed in Punske (2016), which I argue introduced unnecessary complexity to the system. Specifically, Punske (2016) argues for a more sensitive version of Embick's (2007a) local dislocation in his account of (ir)regularity within nominalization.

7 For the sake of simplicity and space, I largely leave aside the question of how many distinct versions of -ing exist in English, which is a point of contention in the literature. 
52 Dissimilation at the Interface: Nominalization as the Key to a Longstanding Puzzle

This model adds a number of mechanisms to local dislocation, giving it access to morphophonological information and allowing it to potentially operate over non-adjacent nodes. I argue that while the spirit of Punske's (2016) analysis is correct, these modifications are unnecessary. Rather, we can adapt the general model to account for the Doubl-ing constraint by simply assuming that local dislocation precedes (or is at least simultaneous with) linearization. If local dislocation is computed over non-linearized strings, the Doubl-ing Filter can easily be derived via independent means. Consider an unacceptable case of double-ing, such as *baffling destroying.

(30) Non-Linearized Structure of *baffling destroying $\{\{\{$ baffl $\}$ ing $\}$ ing $\{$ destroy $\}\}\}$

Concurring with Punske's (2016) diagnosis of the problem here: both -ings are completely insensitive about where they attachmeaning they both could attach to either root. Having the additional ing will not rescue the structure because, since both are dislocating, neither is present for the purposes of computing strict adjacencyonly the roots are. Put another way, baffl and destroy in (30) above are equidistant from each -ing, since both -ings will attempt to dislocate simultaneously. The grammar has no means to force a locally dislocated element to attach to the right root, so a configuration like this will always yield ungrammaticality. Punske (2016) tries to account for the nominal pattern by making -ing more sensitive, that is, giving it awareness of the morphophonological features that surround it. The present account does just the opposite, making -ing completely insensitive, which is more in line with the original spirit of local dislocation.

The hierarchical structure of (30) is given in (31), below: 
(31) Hierarchical Structure of *baffling destroying

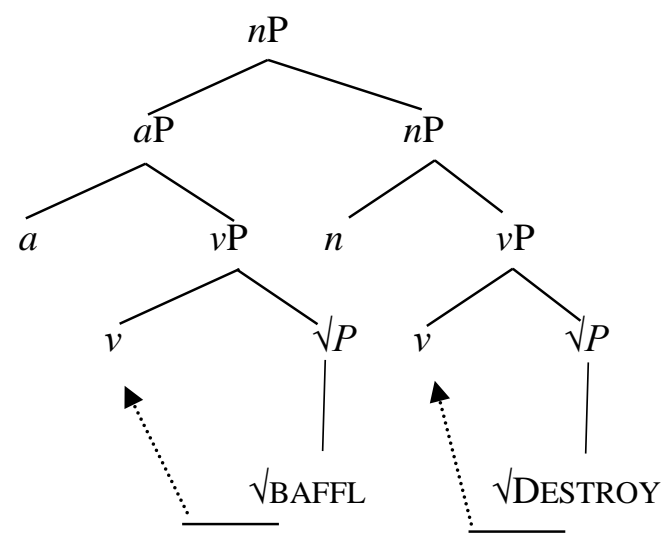

As noted by Myler (2009), in DM, "[i]ndividual affixes are permitted to stipulate whether they are prefixes or suffixes..." (p. 48). That means that asymmetric c-command is not determinate of linear relations in this model, unlike in Kayne's (1994) antisymmetric approach. If we assume that -ing is ambivalent about its linearization, then the nature of the effect becomes readily apparent and we can derive the doubl-ing effect through local dislocation. In such an account, there are several possible linear outputs of (31). Following Myler's (2009) notation, I use '*' to indicate a linear relation between two nodes and ' + ' to indicate local dislocation.

(32) Possible linear outputs of (31)
a. ing $*$ baffl $* \emptyset_{v} *$ ing $*$ destroy $* \emptyset_{v}$
b. ing $*$ baffl $* \emptyset_{v} *$ destroy $* \emptyset_{v} *$ ing
c. baffl $* \emptyset_{v} *$ ing $*$ destroy $* \emptyset_{v} *$ ing
d. baffl $* \emptyset_{v} *$ ing $*$ ing $*$ destroy $* \emptyset_{v}$ 
54 Dissimilation at the Interface: Nominalization as the Key to a Longstanding Puzzle

The linear outputs in (32) and (32) are ultimately responsible for the doubl-ing effect because, as I noted above, the grammar has no means to force a locally dislocated element to attach to its proper host. Thus, (32) would yield a number of possible post-locally dislocated linear orders, including (33) and (34) below:

$$
\begin{aligned}
& \text { baffl } * \emptyset_{v} * \text { destroy } * \emptyset_{v}+\text { ing }+ \text { ing } \\
& \text { baffl } * \emptyset_{v}+\text { ing }+ \text { ing } * \text { destroy } * \emptyset_{v}
\end{aligned}
$$

For both (33) and (34) the issue is quite simple: one element requiring an -ing ends up with none while the other ends up with both. The local dislocation mechanism is just too simplistic to prevent this result, which, as I argued earlier, is a positive thing (and represents an improvement over Punske's (2016) unnecessary complication to the system). This follows from a modification to Richard's (2010) Distinctness: essentially the identical dislocating forms are disallowed within the same linearization domain.

(35) Distinctness (Richards 2010: 5)

If a linearization statement $\langle\alpha, \alpha\rangle$ is generated, the derivation crashes.

Because all of the elements are within the same cyclic domain (phase), the two locally dislocating -ings end up as part of the same linearization statement. The grammar, requiring distinctness, prevents linearization from occurring which results in ungrammaticality. We can conceive of this more simply as the -ing affixes being unable to find the appropriate morphological host because of the multiple possible hosts available.

Key differences emerge because of the types of domains being 
considered. For the present analysis, strict adjacency is no longer relevant: c-command relationships have been lost because the relevant operations are post-syntactic by the time the linearization algorithm is computed for local dislocation. For Richards, strict adjacency (as defined through asymmetric c-command) is the relevant relationship. Thus, the full spell-out domain is relevant for dissimilation through local dislocation. This can be seen in the examples below where the intervention of a non-ing marked adjective does not prevent ungrammaticality.

(36) *The daring quick destroying...

(37) *John's confusing messy leaving...

The examples (36) and (37) are only predicted under an analysis wherein the entire spell-out domain is the linearization domain is relevant. No previous constraint can adequately account for the ungrammaticality of examples like these since the dissimilation effect no longer involves linear adjacency (along with other limitations previously presented for the constraints).

The fundamental underlying principles defining the two are the same: linearization does not like ordering identical elements; when it is called on to do so, the derivation fails. In Richards (2010), languages could implement a variety of strategies to avoid violations of Distinctness: “...including removing offending structure, adding additional structure to insert a phase boundary between identical nodes, blocking movement operations that would create violations, or forcing movement that break up ill-formed structures" (p. 141). Richards further notes that the way a particular language chooses to deal with potential Distinctness violations varies from language to language. How and why a particular language chooses its strategy is 
uncertain. This is also true of Distinctness at the point of local dislocation - with some further restrictions.

Since local dislocation occurs after the point of structure building and movement in the narrow syntax, options such as the addition of new structure and/or blocking or forcing movement would run afoul of Look Ahead prohibitions (see, for instance, Collins 1997). Thus, by prediction, the only options available to languages dealing with Distinctness violations at the point of local dislocation are elision of the offending structure or crash of the derivation. This harkens back to Yip's (1998) conclusion that the ideal form for a doubl-ing candidate is the unpronounced form.

Another chief distinction between the present account and Distinctness as defined in Richards (2010), is that the present account addresses linearization after vocabulary insertion; for Richards (2010), Distinctness was computed before vocabulary insertion (see discussion on pp. 20-22). The present analysis does not propose to supersede Richards' (2010) Distinctness, but to supplement it- to what extent Richard's Distinctness could be captured in the postvocabulary insertion ways discussed here is a question for further, future inquiry. It is necessary that local dislocation-based Distinctness be post-vocabulary insertion to be compatible with the allomorphy analysis presented in Punske (2016), which requires that vocabulary insertion occur 'blindly', introducing a default form.

We can contrast -ing with the English comparative and superlative, discussed by Embick \& Noyer (2001), among others. The comparative and superlative heads are strictly ordered, but can be reordered via local dislocation. However, there is never more than a single linear structure for each of the following examples from Embick \& Noyer (2001: 564). ${ }^{8}$

${ }^{8}$ Embick (2007b) provides a much more detailed discussion of this phenomenon, but 
(38) John is smart-er than Bill.

(39) John is mo-re intelligent than Bill.

(40) *John is intelligent-er than Bill.

(41) ?*John is mo-re smart than Bill.

As noted earlier, the doubl-ing effect does not apply to all nominals equally. Following tests outlined by Grimshaw (1990), it is apparent that event nominals (of which gerunds are a subset) are subject to the doubl-ing effect, while non-event nominals appear not to be. This can be seen in the examples repeated below for clarity:

I will only address a few significant points here. One critical distinction between the nature of the proposed local dislocation of -ing and the local dislocation of the comparative and superlative heads is that the former is insensitive to both phonological and morphological context (again this is a major divergence from Punske (2016)), while the latter needs to show some sensitivity. Embick (2007b) notes that “... synthetic forms are only possible with 'short' adjectives" (p. 9). He further notes that some adjectives fit the general prosodic constraints for hosting the comparative/superlative and yet still seem to disprefer it, at least for some speakers.

(i) \%more clear / \%clearer (Embick 2007b: 9, fn. 5)

(ii) $\%$ more fun $/ \%$ funner

I raise these issues largely in the interest of full disclosure of potentially unresolved issues with the model proposed within this paper. I see two reasonable, possible solutions to the acceptability of whichever of the pair a given speaker accepts out of 0 and 0 . One would be to allow the comparative and the superlative to be sensitive to the phonology and lexical specifications of their potential hosts. The other would be to allow both potential derivations to proceed (one with local dislocation and one without) and continue only with the surviving derivation. Both of these options run somewhat counter to the assumptions of the model developed in this paper - though the first option would be easier to reconcile, requiring only distinct specifications within the given heads. 
58 Dissimilation at the Interface: Nominalization as the Key to a Longstanding Puzzle

(42) *The Romans' baffling destroying of the city turned the populace against the war.

(43) *The daring destroying of the occupied bridge.

(44) Ruby's daring killing of Oswald still sparks the interest of conspiracy theorists.

(45) The baffling killings shocked the beleaguered police.

Thus, the model needs to be able to account for why forms like killing do not seem to participate in the doubl-ing effect. Examples like (44) appear to pose a problem for the model since we might predict them to be ungrammatical.

However, following Punske's (2016) model, the explanation for why these forms don't pattern with the gerunds is apparent. In that model, any morphological element that is lexically specified may not be locally dislocated. The affix -ing in these cases is a specified nominal ending, the evidence being that the resultant forms are not complex event nominals in the sense of Grimshaw (1990).

To summarize, the doubl-ing pattern is an interaction of the local dislocation of -ing affixes (Punske 2016) in complex event nominals (Grimshaw 1990) with Distinctness (Richards 2010). The apparent, puzzling contrasts in grammaticality are due to the structural differences between complex event nominals with -ing affixes and other nominals which have homophonous, but distinct -ing affixes that are lexically specified. Thus, the combination of baffling and destroying (or other similar combinations) in the same linearization (cyclic) domain is illegitimate because it violates the Distinctness prohibition, because both -ings are in need of linearization (local dislocation). In contrast, the combination of baffling and killing is 
Jeffrey Punske 59

accepted because there is only free -ing affix within the linearization domain.

\subsection{Doubl-ing Effect in the Verbal Domain}

This section demonstrates how the present analysis is compatible with previous accounts of the doubl-ing effect, specifically approaches such as Richards (2010) or Nevins (2012), wherein the presence of a cyclic boundary (phase) is sufficient to distinguish between grammatical and ungrammatical instances of doubl-ing. As demonstrated in the previous section, such accounts are insufficient to account for the facts in nominals alone; however, these approaches seem sufficient for the verbal domain.

The canonical examples of the doubl-ing effect (Ross 1972, Milsark 1988, Pullum \& Zwicky 1999) are quite easy to account for within the present account. All of the grammatical examples can be accounted for by assuming that the intervention of a phase boundary disrupts the doubl-ing effect. Such an account is most clearly articulated in Nevins (2012) expanding on Milsark's (1998) approach. Milsark (1988) presents an aggressive constraint to address the doubl-ing facts. For Milsark there is a general constraint ruling out any adjacent -ing forms - which is then constrained by other factors.

(46) The Doubl-ing Filter (Milsark 1988: 626)

At PF, mark as ill-formed any sentence contain contiguous -ing affixed words.

Milsark notes that PRO, which for him is visible at PF because it is case-marked, is sufficient to distinguish between grammatical forms with contiguous -ing versus those that are ungrammatical. Thus, 
60 Dissimilation at the Interface: Nominalization as the Key to a Longstanding Puzzle

under Milsark's (1988) account, (47) is well-formed as it has an intervening PRO between regretting and reading because regret is a control verb, while (48) is ill-formed as no PRO intervenes because keep is not a control verb.

(47) John has been regretting reading the book.

(48) *John was keeping reading the book.

Pullum \& Zwicky (1999) dispute whether PRO is really sufficient to constrain the filter in such a way to accept the grammatical forms because there are far more instances of grammatical adjacent -ing marked forms than what PRO could reasonably account for. Pullum \& Zwicky also dispute Milsark's assumption that there is a single ing suffix in English, arguing instead that the Doubl-ing Filter must ultimately be constrained to a particular instantiation of -ing. Furthermore, they show that Milsark's Doubl-ing Filter predicts certain acceptable sentences to be ungrammatical, since there is no obvious reason to posit PRO in the following examples from Pullum \& Zwicky (1999: 255, 7a-g):

(49) You should report pain during walking or other normal activities.

(50) There was a lot of pushing, shoving, and elbowing of ribs.

(51) They are all going fishing.

(52) It was truly an amazing building.

(53) The novel design made the building amazing. 
(54) We could hear the screaming coming out of the air vents.

(55) Just imagine: aluminum siding selling for a dollar a foot!

Pullum \& Zwicky (1999) state that “...the upper bound on the number of distinct possibilities for two -ing-forms to fall adjacent in a string is $32^{2}-33=1,056 \ldots$ [and]...Milsark's formulation thus fails, literally, a thousand times over" (p. 255). However, as I show shortly, each of these examples are readily captured in a Nevins' (2012) phase-based approach. In contrast, Pullum \& Zwicky argue that the doubl-ing effect is best captured by a filter on local trees, as in (56).

(56) Doubl-ing Filter (third revision) (Pullum \& Zwicky 1999: 261)

The following type of local tree is not permitted:

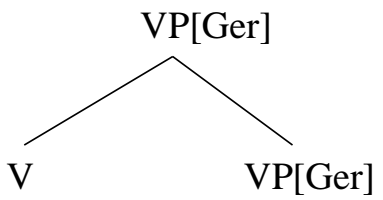

Pullum \& Zwicky contend that one of the stronger attributes of their proposal is the fact that the distinct forms of -ing are still treated as different morphological elements; they echo this by citing earlier work of their own, in which they suggest "the Doubl-ing Constraint is best located as a language-specific codicil to the English instantiation of a universal constituency principle defining VPs" (p. 261). However, because their filter so crucially relies on the definition of a VP, it's not entirely obvious how we could adapt Pullum \& Zwicky's version of the filter to rule out examples like (13) (repeated here as (57)). 
62 Dissimilation at the Interface: Nominalization as the Key to a Longstanding Puzzle

(57) *The baffling destroying of the city...

(Punske 2016: 87)

Given Pullum \& Zwicky's critique, it is clear that a PRO-based analysis is not enough to constrain a Milsark-style filter. Nevins (2012) notes that PRO is unlikely to be the source of the grammaticality distinction at issue here, but rather, instead we should look to the syntactic structure associated with PRO — namely, CP. Given phasetheoretic assumptions including the notion that $\mathrm{C}$ is a phase head and therefore triggers Spell-Out (see, for instance, Chomsky 2001, 2007, Legate 2003, Abels 2012, Gallego 2012, among others), we could assume that the key difference between a grammatical doubl-ing construction and an ungrammatical one is the presence of a phase boundary. Richards (2010) also provides a phase-based account based on transitivity properties of the relevant verbs (see Richards 2010: 5767). Recall, from the discussion of nominals in the previous section, that multiple -ing affixes are disallowed if they are not lexically selected for (that is, if they are required to undergo local dislocation in the sense of Punske 2016). Transferring this assumption into the verbal domain allows us to fully account for the doubl-ing effect. Thus, the Doubl-ing Filter is better understood as a constraint on the cooccurrence of two instances of -ing within a single Spell-Out Domain.

(58) The Doubl-ing Filter (Revised)

$*\{\ldots$-ing ... -ing ... $\}$

In (58), the curly bracket ' $\{$ ' marks the edge of a spell-out domain. This is essentially Milsark's formulation rewritten without specific reference to the sentential level, substituting the notion of a spell-out domain instead. Under this formulation, adjacent -ings within the same spell-out domain are ungrammatical, but surface -ings in different spell-out domains are grammatical. Following Nevins 
(2012), Milsark's PRO-based restriction represents a special case of this more general condition.

This version of the constraint could also be classified as part of the generalized extended constraint from Hiraiwa (2014):

(59) A Phase Theory of Phrasal Adjacency Constraint (Hiraiwa 2014: 22)

Multiple phrases containing PF-identical elements cannot be morphophonologically realized within a single Spell-Out domain at Transfer.

Or, more generally, we may again consider Richards' (2010) Distinctness.

(60) Distinctness (Richards 2010: 5)

If a linearization statement $\langle a, a\rangle$ is generated, the derivation crashes.

Regardless of how we choose to formalize the ban, the theoretic description remains the same: the intervention of a cyclic boundary (phase) will create the necessary conditions for adjacent -ing marked affixes broadly. Within nominals, when -ing is lexically specified (i.e., for non-complex event nominals), it does not participate in the phenomena because it does not locally dislocate and is not subject to Distinctness. With this description in mind, let us reconsider the examples from Pullum \& Zwicky (1999: 255, 7a-g).

(61) You should report pain during walking or other normal activities.

If we allow for DP phases (see Chomsky 2007, Abels 2012, 
64 Dissimilation at the Interface: Nominalization as the Key to a Longstanding Puzzle

others; though, see Matushansky 2005 for a contrary view), walking would be a DP, which would be spelled out and linearized prior to any potential interaction with the -ing associated with during. A reviewer also notes that during may be a lexicalized preposition, which would further remove this example from the relevant analysis.

(62) There was a lot of pushing, shoving, and elbowing of ribs.

Much as with (61), pushing, shoving, and elbowing are all independent DPs and thus would be linearized separately.

(63) They are all going fishing.

If we allow, following Copley (2001), that going heads its own WollP, which is a functional projection hosting the future modal woll (cf. Abusch 1985); WollP is external to the VoiceP phase containing fishing.

(64) It was truly an amazing building.

This example was discussed extensively in the section on nominals. Recall that the interaction of -ing marked adjectives and nominals like building are special because the nominal loses a possible interpretation in the presence of the -ing marked adjective-namely, the complex event interpretation. The reason examples like (64) are possible is that the -ing found in building is lexically selected and not subject to local dislocation nor Distinctness.

(65) The novel design made the building amazing.

This example follows from the same principles as (64). 
(66) We could hear the screaming coming out of the air vents.

(67) Just imagine: aluminum siding selling for a dollar a foot!

Much as (61) and (62), the presence of DP-phases accounts for why (66) and (67) are acceptable. Neither screaming and coming (66) nor sliding and selling in (67) are part of the same linearization domain, so they are not subject to Distinctness.

\section{Other Dissimilation Phenomena}

The analysis presented here can be viewed as a supplement to Richards' (2010) Distinctness proposal. The present analysis predicts that there is a derivational point where Distinctness applies after vocabulary insertion (and also narrow syntax). In this section, I examine other possible instances of the derivational account.

\subsection{Japanese Double-o}

One potential benefit of the approach outlined here is that it allows us to possibly discard language-specific haplology constraints of the types proposed for the English doubl-ing phenomena. Under the present account, it is the interaction of the particular nature of the relevant Vocabulary Items (in this case, -ing) and Punske (2016) styles Local Dislocation as mediated through Distinctness. As such, we would anticipate to find examples cross-linguistically.

Tentatively, I examine the case of the Japanese Double-o constraint (Kuroda 1965, Harada 1973/1986; for recent approaches see Hiraiwa 2010a, b). This constraint, descriptively, is a prohibition on "multiple occurrences of the accusative case particle $o$ under certain conditions" 
66 Dissimilation at the Interface: Nominalization as the Key to a Longstanding Puzzle

(Hiraiwa 2010b: 724). Classic examples are given below.

$\begin{array}{llll}\text { *Hanako-ga } & \text { Taroo-o } & \text { hon-o } & \text { yom-aseru } \\ \text { Hanako-NOM } & \text { Taroo-ACC } & \text { book-ACC } & \text { read-CAUS } \\ \text { 'Hanako makes } & \text { Taroo read a book' } & \end{array}$

$\begin{array}{lllll}\text { *Hanako-ga } & \text { Taroo-ni } & \text { toti-o } & \text { zyooto-o } & \text { sita } \\ \text { Hanako-NOM } & \text { Taroo-DAT } & \text { land-ACC } & \text { giving-ACC } & \text { did } \\ \text { 'Hanako gave } & \text { Taroo a piece of land' } & & \end{array}$

(Richards 2010: 114)

Much like the doubl-ing constraint in English, the ban is not absolute. Numerous grammatical examples with multiple accusatives are found in Japanese. Hiraiwa (2010a) provides a useful typology of the grammatical forms, which include: scrambling, prosodic boundaries, clefting, and clear CP boundaries. Hiraiwa (2010a) also notes that suppression of one of the arguments may also rescue an ill-formed example.

For Hiraiwa, much like for the present account and Richards (2010), the role of multiple spell-out/phases is critical to the account. Hiraiwa (2010a) presents a general constraint, mediated by spell-out domains, the SYNTACTIC OCP:

(70) ThE Syntactic OCP (Hiraiwa 2010a: 37)

Multiple elements with an identical morphophonological specification are disallowed in the same Spell-Out domain at PF.

As we can see, even with the restriction to Spell-Out domains, the constraint presented in (70) would over-predict, as halpological effects are not universally found for all morphophonologically identical elements. As Hiraiwa notes in his analysis of Japanese, this 
constraint only applies to the accusative in Japanese and not to the nominative or genitive (see discussion in Hiraiwa 2010b: 45). Thus, for Hiraiwa, the general, universal constraint in (70) is realized in Japanese as THE DOUBLE- $O$ CONSTRAINT:

(71) The Double- $O$ Constraint (Hiraiwa 2010a:36, Hiraiwa 2010b:753)

Multiple identical occurrences of the structural accusative Case value cannot be morphophonologically realized within a single Spell-Out domain at Transfer.

However, the analysis offered here makes no reference to any particulars of English morphology. Rather, the principles argued to underlie the doubl-ing effect are argued to be universal: if two (identical) locally dislocated forms are found in the same linearization domain (phase domain), they create an incomputable linearization. This analysis is thus fundamentally not about the doubl-ing effect or a parochial property of English grammar, but rather a universal property of local dislocation.

Richards (2010) suggests that Japanese Double-o Constraint facts may be captured by the same structural account he provides for Kinande (see p. 125). I follow Richards (2010) in suggesting that a full account along the lines sketched throughout. Further suggestions that the Japanese Double-o Constraint may be due to identical or similar derivational effects at linearization follow from the morphological status of -o, which, like -ing, does not appear to be a general trigger for contextual allomorphy, and the lack of strict adjacency needed to trigger the effect. Nevins (2012) likewise suggests that the effect is "...squarely in the realm of linearizationlevel haplology" (p. 111). 


\subsection{Possible Post-vocabulary Item Distinctness as Deletion}

This means that many options for recusing a potential violation of Distinctness are no longer available (movement, blocking movement, insertion of new structure, altering the structure/form). In the case of English doubl-ing, this violation causes the derivation to crash. However, we would also expect languages to utilize a deletion strategy to rescue a potential violation.

Mandarin le deletion may provide us with an example of deletionas-rescue strategy predicted by the analysis. There are some key differences between the Mandarin phenomena, which may temper our results. The relevant dissimilation is between two different le forms: a perfective maker and a sentence final particle (see $\mathrm{Li} \&$ Thompson 1981). In Mandarin, adjacency is critical. This can be seen in the following examples from Yip (1998: 227):

$\begin{array}{llllll}\text { Wo he-le } & \text { san bei } & \text { kafei } & \text { le } \\ \text { I drink-PF } & \text { three } & \text { cups } & \text { coffee } & \text { CRS }^{9} \\ \text { 'I drank three cups of coffee' }\end{array}$

$\begin{array}{llll}\text { Bing } & \text { dou } & \text { hua } & \text { le }(* \mathbf{l e}) \\ \text { ice } & \text { all } & \text { melted } & \text { PF/CRS }\end{array}$

'The ice all melted'

In (72), both $l e$ 's are possible because they are not adjacent, whereas they are adjacent in (73) (and therefore impossible). Erlewine (2017) argues that le (along with other 'low particles') occupies "...the head realized by low SFPs [sentence final particle] as the head of the lower phase in the clause, which has traditionally been equated with vP"

9 CR stands for 'Current Relevant State' (Yip 1998). 
(p. 38). By assumption, this should put the sentence final particle in a position to interfere with the perfective particle (or vice versa).

What may distinguish the Mandarin case from English doubl-ing is the fact that in Mandarin, it is unlikely that both le elements are undergoing local dislocation. Rather, it is the presence of the sentence final particle at the target sight of displacement of the aspect marker le which prevents both from surfacing. The details of such an analysis are tentative, but have some promise. I leave open the question of whether Mandarin le deletion is a true illustration of the analysis proposed here for future research.

In general, the analysis predicts that haplology of this type (postvocabulary insertion) should exist cross-linguistically. Such postvocabulary insertion, haplology-driven by Richards' Distinctness, may be linearly insensitive (English doubl-ing); if it is linearly sensitive, it must be due to the fact that only one element is dislocating (as in the potential example of Mandarin). Like all other forms of Distinctness, post-vocabulary insertion Distinctness is bound to a spell-out domain.

The analysis is relatively narrow in its predictions: it provides a supplement to Richards' (2010) Distinctness wherein elements undergoing local dislocation (as described in Punske 2016) may interfere with each other (or potentially be interfered with, if the suggestions about Mandarin are on the right track). Thus, it is not a full account of dissimilation/haplology cross-linguistically; nor does it try to be.

It is worth briefly considering some cases of dissimilation that do not fall within a post-vocabulary insertion Distinctness explanation. We examine data from Dutch, drawn from Neeleman and van de Koot (2006), involving a ban on repeated er 'there' forms.

In Dutch, multiple instances of er 'there' are generally disallowed. Though, as Neeleman and van de Koot (2006) note "...the 
70 Dissimilation at the Interface: Nominalization as the Key to a Longstanding Puzzle

quantificational er can co-occur with expletive, locative, and prepositional er" (p. 692). Illustrative examples are provided below:

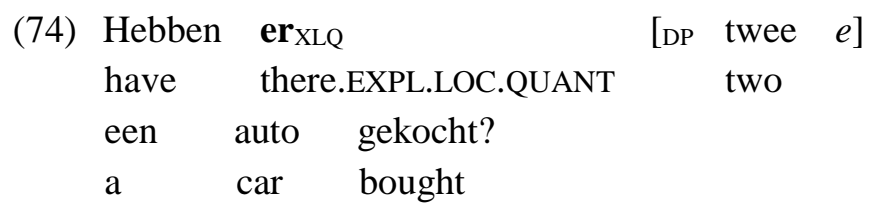

'Did two (of them) buy a car there?'

(75)

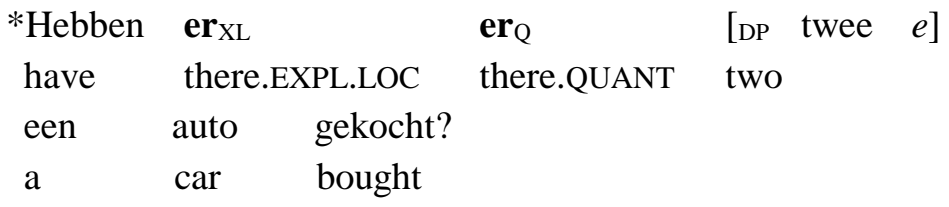

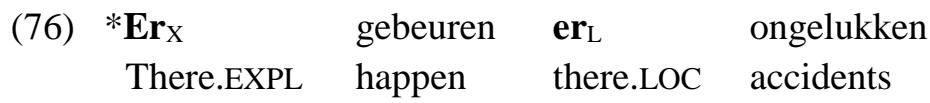

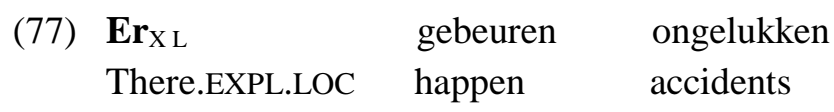

'Accidents happen there'

(Neelman \& van de Koot 2006: 693-694)

The examples show that a single $e r$ will absorb the functions of the other er's. Neelman and van de Koot (2006) suggest an interaction between syntax and haplological rules to derive the phenomenon (the full details of this analysis are provided on p. 695). Their analysis has some details that are suggestive that the Dutch er facts may be able to be captured by the pre-vocabulary item Distinctness of Richards (2010). Specifically, there is a preference for movement ("over suppression of semantic content" (p. 695) and the haplology rules must make reference to specific syntactic categories. One challenge is 
that the haplology rules also make reference to phonological identity.

Thus, the analysis presented here provides another piece in the puzzle towards addressing morphological dissimilation, but it does not presuppose itself to be the only answer. One recurring theme within the literature on morphological dissimilation is the need for lexical specification or constraint targeting specific lexical items. The proposed analysis provides some means for us to approach these problems without the need for specific constraints. However, the core idea of lexical specification is not eliminated. The reason that the doubl-ing effect exists in English is because of the lexical properties of -ing: where it is introduced in the derivation, the fact that it must locally dislocate, etc. All of these facts, which are part of -ing's lexical specification, conspire to derive a dissimilation effect. Presumably, other lexically specified dissimilation effects can also be captured through such conspiracy, though their particular derivations are unlikely to be identical to English -ing.

\section{Conclusion}

This analysis solves a long-standing puzzle in English morphosyntax: why some, but not all, instances of adjacent -ing marked forms are ungrammatical. The solution relies entirely on independent mechanisms of the grammar, not requiring any special rules or constraints dedicated to the phenomenon. If we assume, following Punske (2016), that most -ings are subject to local dislocation, then whenever multiple ings are found within the same linearization domain (phase), the result will be ungrammaticality. This follows from an extension of Richards' (2010) Distinctness. Here were have two identical forms locally dislocating within the same domain and the grammar rejects it for violating Distinctness. 
72 Dissimilation at the Interface: Nominalization as the Key to a Longstanding Puzzle

The many exceptions to the doubl-ing effect are explained by one of two possible structural or morphosyntactic distinctions: phase boundaries that separate the two occurrences or the presence of an ing suffix that is not subject to local dislocation. The doubl-ing effect only occurs when two locally dislocated -ing forms are found within the same spell-out domain. Adjacent -ing forms can be acceptable when a phase boundary intervenes, since they are not part of the same linearization domain. Similarly, multiple -ing marked forms can be found within a single phase, provided that only one -ing is subject to local dislocation (i.e., the other -ings are lexically selected (possibly non-gerundive), as in killing or building).

The analysis presented here makes a straightforward and testable prediction: local dislocation of multiple elements in a cyclic domain with multiple potential hosts should always result in ungrammaticality. This follows from a natural extension of Richards' (2010) Distinctness. For this analysis to be a true solution to the doubl-ing puzzle, these mechanisms must be universally constrained in this way.

Unlike previous solutions to this puzzle, the account developed here requires no specific reference to English morphology or the English lexicon, which also answers one of Pullum \& Zwicky's (1999) principal objections to Milsark's (1988) formulation of the Doubl-ing Filter and other analyses that follow similar lines of general reasoning. As Pullum \& Zwicky note, “[Milsark's] strategy is to present a highly over-general description of some phenomenon and then try to show that appropriate principles of Universal Grammar (UG) can rein in the excess generality" (p. 252). This strategy is similarly adopted by the present analysis, though it avoids the second half of Pullum \& Zwicky's objection.

I concur with Pullum \& Zwicky that Milsark's analysis falls into this trap; as they observe, "it seems ... most unlikely that reliable principles of UG will arise out of unreliable description at the 
parochial (that is, non-universal) level" (p. 252). Indeed, Milsark's formulation requires specific reference to English morphology (banning contiguous -ing marked forms at PF), and thus cannot be viewed as a universal principle.

\section{References}

Abels, K. 2012. Phases: An Essay on Cyclicity in Syntax. Berlin: Walter de Gruyter.

Abusch, D. 1985. On Verbs and Time. Ph.D. Dissertation, University of Massachusetts.

Ackema, P. 2001. Colliding Complementizers in Dutch: Another Syntactic OCP Effect. Linguistic Inquiry 32, 717-727.

Adger, D. 2007. Stress and Phasal Syntax. Linguistic Analysis 33, 238-266.

Borer, H. 1990. V + ing: It Walks Like an Adjective, It Talks Like an Adjective. Linguistic Inquiry 21, 95-103.

Chomsky, N. 2001. Derivation by Phase. In M. Kenstowicz (ed.), Ken Hale: A Life in Language 1-52. Cambridge, MA: MIT Press.

Chomsky, N. 2007. Approaching UG from below. In U. Sauerland \&

H. Gartner (eds.), Interfaces + Recursion = Language $?$ 1-29.

Berlin: Mouton de Gruyter.

Collins, C. 1997. Local Economy. Cambridge, MA: MIT Press.

Copley, B. 2001. Be Going to as a Case of High Aspect. In R. Hastings et al. (eds.), Proceedings from Semantics and Linguistic Theory XI 95-113. Ithaca, NY: Cornell University.

Dobashi, Y. 2003. Phonological Phrasing and Syntactic Derivation. Ph.D. Dissertation, Cornell University.

Embick, D. 2007a. Linearization and Local Dislocation: Derivational Mechanics and Interactions. Linguistic Analysis 33, 303-336. 
74 Dissimilation at the Interface: Nominalization as the Key to a Longstanding Puzzle

Embick, D. 2007b. Blocking Effects and Analytic/Synthetic Alternations. Natural Language and Linguistic Theory 25, 1-37. Embick, D. \& R. Noyer. 2001. Movement Operations after Syntax. Linguistic Inquiry 32, 555-595.

Emonds, J. 1973. Alternatives to Global Constraints. Glossa 7, 39-62.

Emonds, J. 1976. A Transformational Approach to English Syntax: Root, Structure-Preserving, and Local Transformations. New York: Academic Press.

Emonds, J. 1991. The Autonomy of the (syntactic) Lexicon and Syntax: Insertion Conditions for Derivational and Inflectional Morphemes. In C. Georgopoulos \& R. Ishihara (eds.), Interdisciplinary Approaches to Language: Essays in Honor of S.-Y. Kuroda 119148. Dordrecht: Springer.

Erlewine, M. 2017. Low Sentence-Final Particles in Mandarin Chinese and the Final-over-Final Constraint. Journal of East Asian Linguistics 26, 37-75.

Gallego, A. 2012. Phases: Developing the Framework. Berlin: De Gruyter Mouton.

Grimshaw, J. 1990. Argument Structure. Cambridge, MA: MIT Press. Harada, S. 1973/1986. Counter Equi NP Deletion. Journal of Japanese Linguistics 11, 157-202. Reprinted from Annual Bulletin 7 (1973) of the Research Institute of Logopedics and Phoniatrics, University of Toyko.

Hiraiwa, K. 2010a. The Syntactic OCP. The Proceedings of the Eleventh Tokyo Conference on Psycholinguistics 35-56.

Hiraiwa, K. 2010b. Spelling Out the Double-o Constraint. Natural Language and Linguistic Theory 28, 723-770.

Hiraiwa, K. 2014. Constraining Doubling. In K. Nasukawa \& H. van Riemsdijk (eds.), Identity Relations in Grammar 225-254. Berlin: De Gruyter Mouton.

Kayne, R. 1994. The Antisymmetry of Syntax. Cambridge, MA: MIT 
Press.

Kuroda, S-Y. 1965. Generative Grammatical Studies in the Japanese Language. Ph.D. Dissertation, MIT.

Leben, W. 1973. Supersegmental Phonology. Ph.D. Dissertation, MIT.

Legate, J. 2003. Some Interface Properties of the Phase. Linguistic Inquiry 34, 506-515.

Li, C. \& S. Thompson. 1981. Mandarin Chinese: A Functional Reference Grammar. Berkeley, CA: University of California Press.

Menn, L. \& B. MacWhinney. 1984. The Repeated Morph Constraint: Toward an Explanation. Language 60, 519-541.

Milsark, G. 1972. Re: Doubl-ing. Linguistic Inquiry 3, 542-549.

Milsark, G. 1988. Singl-ing. Linguistic Inquiry 19, 611-634.

Milsark, G. 2006. Gerundive Nominalizations. In M. Everaert \& H. van Riemsdijk (eds.), The Blackwell Companion to Syntax vol. II 436-458. Malden, MA: Wiley-Blackwell.

Mohanan, T. 1994. Case OCP: A Constraint on Word Order in Hindi. In M. Butt et al. (eds.), Theoretic Perspectives on Word Order in South Asian Languages 185-216. Stanford, CA: CSLI Publications.

Myler, N. 2009. Linearization and Post-Syntactic Operations in the Quechua DP. Cambridge Occasional Papers in Linguistics 5, 46-66.

Neeleman, A. \& H. van de Koot. 2006. Syntactic Haplology. In M. Evaraert \& H. van Riemsdijk (eds.), The Blackwell Companion to Syntax IV 685-710. London: Blackwell.

Nevins, A. 2012. Haplological Dissimilation at Distinct Stages of Exponence. In J. Trommer (ed.), The Morphology and Phonology of Exponence 84-116. Oxford: OUP.

Pullum, G. 1974. Restating Doubl-ing. Glossa 8, 109-120.

Pullum, G. \& A. Zwicky. 1999. Gerund Participles and HeadComplement Inflection Conditions. In P. Collins \& D. Lee 
76 Dissimilation at the Interface: Nominalization as the Key to a Longstanding Puzzle

(eds.), The Clause in English: In Honour of Rodney Huddleston 251-271. Amsterdam: John Benjamins.

Punske, J. 2016. Cyclicity versus Movement: English Nominalization and Syntactic Approaches to Morpho-Phonological Regularity. Canadian Journal of Linguistics 61, 68-97.

Richards, N. 2001. A Distinctness Condition on Linearization. In M. Karine \& B. Anne (eds.), Proceedings of the 20th West Coast Conference on Formal Linguistics 470-483. Somerville, MA: Cascadilla Press.

Richards, N. 2010. Uttering Trees. Cambridge, MA: MIT Press.

Ross, J. 1972. Doub-ling. Linguistic Inquiry 3, 61-86.

Samuels, B. 2011. Phonological Architecture: A Biolinguistic Approach. Oxford: OUP.

Walter, M. 2007. Repetition Avoidance in Human Language. Ph.D. Dissertation, MIT.

Yip, M. 1988. The Obligatory Contour Principle and Phonological Rules: A Loss of Identity. Linguistic Inquiry 19, 65-100.

Yip, M. 1998. Identity Avoidance in Phonology and Morphology. In S. LaPointe et al. (eds.), Morphology and Its Relation to Phonology and Syntax 216-246. Stanford, CA: CSLI Publications. 